\title{
Highlights from the European society of cardiology congress 2020
}

\author{
Pooneh Nabavizadeh ${ }^{1} \cdot$ Dylan L. Steen $^{1}$ (D) \\ Accepted: 2 December 2020 / Published online: 6 January 2021 \\ ๑) Springer Science+Business Media, LLC, part of Springer Nature 2021
}

After another exciting conference, this article highlights some of the many studies presented. Below, we start with some of the clinically impactful studies that demonstrated statistically significant primary endpoint results.

\section{Early rhythm control in patients with early atrial fibrillation reduced cardiovascular events}

Early Treatment of Atrial Fibrillation for Stroke Prevention Trial (EAST-AFNET 4) was a multicenter, open, 1:1 randomized study that tested a strategy of early rhythm control therapy versus usual care in patients diagnosed with atrial fibrillation within one year [1]. The study enrolled patients diagnosed $\leq 12$ months before enrollment who met one of the following criteria: (1) age $>75$ years; (2) a prior history of stroke or transient ischemic attack; or (3) the presence of two other high-risk conditions. Early rhythm control included antiarrhythmic drugs and/or atrial fibrillation ablation, as well as cardioversion for persistent atrial fibrillation. The primary outcome was a composite of cardiovascular (CV) death, stroke, heart failure (HF) hospitalization, or acute coronary syndrome. A total of 2789 patients were randomized. The trial was stopped for efficacy at a median follow up of 5.1 years.

The mean age was 70 years and $46 \%$ were female. Patients were enrolled a median of 36 days after the first diagnosis of atrial fibrillation. In the early rhythm control group, $94.8 \%$ received an antiarrhythmic drug or underwent atrial fibrillation ablation. The primary outcome occurred less often with early rhythm control (HR $0.79,0.66$ to 0.94 , $\mathrm{P}=0.005$ ). The absolute difference in risk was 1.1 events per 100 person-years. These findings favoring a strategy of early rhythm control versus rate control might be explained

\footnotetext{
Dylan L. Steen

dylan.steen@uc.edu

1 University of Cincinnati, Cincinnati, Ohio, USA
}

by having patients enrolled shortly after diagnosis of atrial fibrillation, use of modern atrial fibrillation ablation techniques, and guidance on the safe use of antiarrhythmic drugs [2].

\section{Empagliflozin demonstrates additional evidence of efficacy in heart failure}

The Empagliflozin Outcome Trial in Patients with Chronic Heart Failure and a Reduced Ejection Fraction (EMPERORReduced) was a 1:1 randomized, double-blinded, parallelgroup, placebo-controlled study testing empagliflozin $10 \mathrm{mg}$ daily versus placebo in chronic HF patients enriched for greater severity of left ventricular (LV) systolic dysfunction than in past trials [3]. Enrollment criteria included: (1) age $\geq 18$ years and (2) LV ejection fraction (LVEF) $\leq 40 \%$. Those with LVEF $31-40 \%$ needed to have a history of HF hospitalization within 12 months or higher levels of N-terminal prohormone natriuretic peptide (NT-preBNP). The primary outcome was a composite of $\mathrm{CV}$ death or hospitalization for HF. A total of 3730 patients were randomized. Median duration of follow-up was 16 months.

The mean age was 67 years, mean LVEF was $27 \%$, median NT-proBNP was $1907 \mathrm{pg} / \mathrm{ml}, 50 \%$ had diabetes mellitus, $48 \%$ had chronic kidney disease stage III or worse. The primary outcome occurred in $19.4 \%$ in the empagliflozin group and $24.7 \%$ in the placebo group (HR 0.75, 0.65 to $0.86, \mathrm{P}<0.001$ ) (Table 1). The effect of empagliflozin on the primary outcome was consistent across subgroups, including the presence of diabetes or the concomitant use of sacubitril-valsartan. These data support the findings of the DAPA-HF trial and suggest that sodium-glucose cotransporter 2 (SGLT2) inhibitors have a beneficial effect on HF outcomes as well as renal function in a chronic HF population regardless of the presence of diabetes [4]. 
Table 1 Efficacy outcomes for empagliflozin in EMPERIORReduced

\begin{tabular}{lllll}
\hline & Empagliflozin & Placebo & HR (95\% CI) & $P$ value \\
\hline CV death or hospitalization for HF & $361(19.4)$ & $462(24.7)$ & $0.75(0.65-0.86)$ & $<0.001$ \\
Hospitalization for HF & $246(13.2)$ & $342(18.3)$ & $0.69(0.59-0.81)$ & \\
CV death & $187(10.0)$ & $202(10.8)$ & $0.92(0.75-1.12)$ & \\
Total HF hospitalizations & 388 & 553 & $0.70(0.58-0.85)$ & $<0.001$ \\
Mean slope of $\Delta$ in eGFR per year & $0.55 \pm 0.23$ & $-2.28 \pm 0.23$ & $1.73(1.10-2.37)$ & $<0.001$ \\
\hline
\end{tabular}

$C V$ cardiovascular, $C I$ confidence intervals, $H R$ hazard ratio, eGFR estimated glomerular filtration rate (units of $\mathrm{ml} / \mathrm{min} / 1.73 \mathrm{~m}^{2}$ )

\section{Ground-breaking trial demonstrates broad benefits with mavacamten for patients with symptomatic hypertrophic obstructive cardiomyopathy}

Clinical Study to Evaluate Mavacamten (MYK-461) in Adults With Symptomatic Obstructive Hypertrophic Cardiomyopathy (EXPLORER-HCM) was a phase 3, 1:1 randomized, double-blind trial which tested the first-in-class, selective allosteric inhibitor of cardiac myosin ATPase compared to placebo [5]. Inclusion criteria were: (1) diagnosis of hypertrophic obstructive cardiomyopathy (HOCM); (2) peak left ventricular outflow tract (LVOT) gradient $\geq 50 \mathrm{~mm} \mathrm{Hg}$ at rest; (3) LVEF $\geq 55 \%$; and (4) New York Heart Association (NYHA) class II-III symptoms. Mavacamten was started at $5 \mathrm{mg}$ daily with blinded dose titrations at weeks 8 and 14. Dose adjustment was done to achieve target plasma concentrations between 350 and $700 \mathrm{ng} / \mathrm{ml}$ and reduction in LVOT gradient to $<30 \mathrm{~mm} \mathrm{Hg}$. The primary composite endpoint measured at week 30 was either $\geq 1.5 \mathrm{~mL} / \mathrm{kg} / \mathrm{min}$ in $\mathrm{pVO}_{2}$ and $\geq 1$ NYHA class reduction or $\geq 3.0 \mathrm{~mL} / \mathrm{kg} / \mathrm{min}$ in $\mathrm{pVO}_{2}$ without worsening of NYHA class. The study cohort was 251 randomized patients.

The mean age of partici pants was 58.5 years, $73 \%$ had NYHA class II symptoms at baseline and $92 \%$ were on a $\beta$ blocker or calcium channel blocker. The primary endpoint occurred in $37 \%$ on mavacamten and $17 \%$ on placebo (19.4\%, 8.7-30.1, $\mathrm{P}=0.0005)$. All other secondary endpoints were also significantly improved with mavacamten. Remarkably, complete response to therapy defined as reduction in all LVOT gradients to $<30 \mathrm{~mm} \mathrm{Hg}$ and achieving NYHA class I was seen in $27 \%$ on mavacamten compared to $<1 \%$ on placebo. This study was the first significant validation of efficacy from a compound targeting the primary pathophysiology of HOCM [6].

\section{Colchicine now also demonstrates efficacy in patients with chronic coronary artery disease}

The second Low Dose Colchicine (LoDoCo2) trial tested whether colchicine, an anti-inflammatory drug that inhibits tubulin polymerization and alters leukocyte responsiveness, reduces cardiovascular outcomes in patients with chronic coronary artery disease (CAD) [7]. Enrollment criteria included: (1) age 35-82 years; (2) CAD on coronary angiography or a coronary artery calcium score of $\geq 400$ Agatston units; and (3) clinically stable condition for $\geq 6$ months. Exclusion criteria were moderate-to-severe renal impairment, severe heart failure, or history of known side effects from colchicine. After a run-in period, patients were 1:1 randomized to colchicine 0.5 daily versus placebo. The primary end point was a composite of $\mathrm{CV}$ death, spontaneous myocardial infarction (MI), ischemic stroke, or ischemia-driven coronary revascularization. A total of 5522 patients underwent randomization. Median follow-up was 28.6 months.

The mean age was 66 years, $15.3 \%$ were female, and statin use was $94 \%$. The primary endpoint occurred in $6.8 \%$ of patients in the colchicine group and in $9.6 \%$ of patients in the placebo group (HR $0.69,0.57-0.83, \mathrm{P}<0.001$ ) (Table 2). The results of this trial indicate potential anti-inflammatory benefit from colchicine in consistent with those from the LoDoCo and COLCAT trials. Of note, the benefits of colchicine occurred on top of standard of care therapies. These benefits appeared early and appeared to accrue over time [8]. 
Table 2 Key endpoints in LoDoCo2 with hierarchical testing

\begin{tabular}{lllll}
\hline & Colchicine (\%) & Placebo (\%) & HR (95\% CI) & $P$ Value \\
\hline $\begin{array}{l}\text { CV death, MI, ischemic stroke, or } \\
\text { ischemic-driven revascularization }\end{array}$ & 6.8 & 9.6 & $0.69(0.57-0.83)$ & $<0.001$ \\
CV death, MI, or ischemic stroke & 4.2 & 5.7 & $0.72(0.57-0.92)$ & 0.007 \\
MI or ischemia-driven revascularization & 5.6 & 8.1 & $0.67(0.55-0.83)$ & $<0.001$ \\
CV death or MI & 3.6 & 5.0 & $0.71(0.55-0.92)$ & 0.01 \\
Ischemia-driven revascularization & 4.9 & 6.4 & $0.75(0.60-0.94)$ & 0.01 \\
MI & 1.1 & 1.5 & $0.70(0.53-0.93)$ & 0.01 \\
Ischemic stroke & 0.6 & 0.9 & $0.66(0.35-1.25)$ & 0.20 \\
All-cause death & 2.6 & 2.0 & $1.21(0.86-1.71)$ & No test \\
CV death & 0.7 & 0.9 & $0.80(0.44-1.44)$ & No test \\
\hline
\end{tabular}

$C V$ cardiovascular, $M I$ myocardial infarction, $C I$ confidence intervals, $H R$ hazard ratio

\section{Less bleeding after transcatheter aortic valve implantation with aspirin monotherapy than with aspirin plus clopidogrel}

The POPular TAVI (Antiplatelet Therapy for Patients Undergoing Transcatheter Aortic Valve Implantation) tested aspirin versus aspirin plus 3 months of clopidogrel on bleeding in patients undergoing TAVI. Exclusion criteria: (1) no indication for long-term oral anticoagulation and (2) recent coronary artery stent implantation $(<3$ months for drug-eluting stent and $<1$ month for bare metal stent). A total of 690 patients were 1:1 randomized in this open-label study. The two primary outcomes were all bleeding and non-procedurerelated bleeding over 12 months [9].

The mean age was 80 years and $48.7 \%$ were female. Bleeding of any type occurred in $15.1 \%$ of the aspirin alone arm and in $26.6 \%$ of the aspirin plus clopidogrel group (RR $0.57,0.42-0.77, \mathrm{P}=0.001)$. Non-procedure-related bleeding occurred in $15.1 \%$ and $24.9 \%$ of each arm, respectively (RR 0.61, 0.44-0.83, $\mathrm{P}=0.005$ ). Aspirin monotherapy was also associated with a lower incidence of $\mathrm{CV}$ death, stroke, $\mathrm{MI}$, or non-procedure-related bleeding. Guideline recommendations for aspirin and clopidogrel following TAVI may now warrant revision.

\section{Other conference highlights}

There were also many important studies with non-statistically significant findings, but important clinical implications. These are discussed briefly in the following paragraphs.

BRACE CORONA trial investigated continuing vs suspending Angiotensin-converting enzyme inhibitors (ACEIs) or angiotensin receptor blockers (ARBs) in patients diagnosed with Coronavirus disease 2019 (COVID-19) [10]. This trial enrolled a total of 659 patients hospitalized with COVID-19 and on chronic therapy with ACEIs or ARBs and randomized them to suspension of ACEI/ARB vs continued use of those medications. Days alive and outside of the hospital at 30 days (primary outcome) and all-cause death at 30 days (secondary outcome) were not statistically different in those groups. Of note, patients who were hemodynamically unstable, on mechanical ventilation, on more than 3 antihypertensives, were taking sacubitril/valsartan, or had a history of hospitalization for decompensated heart failure in the prior 12 months were excluded from this study.

BAMI trial compared intracoronary infusion of bone marrow-derived mononuclear cells with standard therapy in patients with acute ST elevation myocardial infarction (STEMI) who underwent successful reperfusion therapy [11]. This randomized, open-label trial enrolled 375 eligible patients and did not show any statistically significant difference in all-cause mortality at 2 years (primary outcomes) and cardiovascular death or hospitalization due to heart failure (secondary endpoint) between the study groups [12].

DUBIUS trial compared downstream vs upstream administration of $\mathrm{P}_{2} \mathrm{Y}_{12}$ inhibitors in patients with non-ST elevation acute coronary syndrome (NSTE-ACS) undergoing percutaneous coronary intervention (PCI) [13]. This randomized, open-label trial randomized patients to pretreatment with ticagrelor before undergoing angiography (upstream $\mathrm{P}_{2} \mathrm{Y}_{12}$ inhibition) vs treatment with $\mathrm{P}_{2} \mathrm{Y}_{12}$ inhibitors after angiography and prior to $\mathrm{PCI}$ (downstream $\mathrm{P}_{2} \mathrm{Y}_{12}$ inhibition). Patients in the downstream $\mathrm{P}_{2} \mathrm{Y}_{12}$ inhibition treatment group were further randomized to receive ticagrelor vs prasugrel. Between the treatment groups, there was no significant difference in the primary outcome defined as a composite of death from vascular causes, non-fatal myocardial infarction, non-fatal stroke and major or fatal bleeding at 30 days after randomization. Of Note, this trial excluded patients who were on chronic oral anticoagulation [14].

ATPCI trial evaluated anti-anginal treatment with trimetazidine vs placebo in patients with recent successful PCI [15]. A total of 6007 patients within 30 days following a successful PCI for stable or unstable coronary artery disease 
were randomized to receive trimetazidine $35 \mathrm{mg}$ twice daily or matching placebo. Patients were followed up for a median of 47.5 months and there was no significant difference in the primary composite endpoints defined as cardiac death, hospital admission for cardiac events, or persistent angina requiring adding, switching, or increasing the dose of antianginal medications or leading to coronary angiography [16].

REALITY trial compared a restrictive red blood cell transfusion strategy vs a liberal strategy in patients with recent acute myocardial infarction (AMI) and anemia. Patient with AMI and hemoglobin $(\mathrm{Hb}) \leq 10 \mathrm{~g} / \mathrm{dL}$ and $>7 \mathrm{~g} /$ $\mathrm{dL}$ were enrolled and those with cardiogenic shock, post PCI or CABG AMI, life-threatening or massive bleeding, history of transfusion in the previous 30 days and history of malignant hematologic disease were excluded from the study. A total of 666 patients were randomized in a 1:1 fashion to transfusion with either a liberal strategy (defined as transfusion when $\mathrm{Hb} \leq 10 \mathrm{~g} / \mathrm{dL}$ with a goal of $>11 \mathrm{~g} / \mathrm{dL}$ ) or a restrictive strategy (defined as transfusion when $\mathrm{Hb} \leq 8 \mathrm{~g} /$ $\mathrm{dL}$ with a goal of $8-10 \mathrm{~g} / \mathrm{dL}$ ). The primary endpoint defined as the 30-day composite of all-cause mortality, non-fatal stroke, non-fatal recurrent MI, and emergency revascularization prompted by ischemia was not statistically different between the arms and indicated noninferiority of the restrictive strategy.

Finally, we encourage readers to explore the broader content of the ESC presentations for other interesting studies and other topics of interest. As an example, the 2020 ESC provided new guidelines on Atrial Fibrillation [17], Non-STSegment Elevation Acute Coronary Syndromes [18], Sports Cardiology and Exercise in Patients with Cardiovascular Disease [19] and Adult Congenital Heart Disease [20].

\section{References}

1. Kirchhof P, Camm AJ, Goette A et al (2020) Early RhythmControl Therapy in Patients with Atrial Fibrillation. NEJM 383(14):1305-1316

2. Bunch TJ, Steinberg BA (2020) Revisiting rate versus rhythm control in atrial fibrillation- timing matters. NEJM 383(14):1383-1384

3. Packer M, Anker SD, Butler J et al (2020) Cardiovascular and renal outcomes with empagliflozin in heart failure. NEJM 383(15):1413-1424

4. Jarcho JA (2020) More evidence for SGLT2 inhibitors in heart failure. NEJM 383(15):1481-1482

5. Olivotto I, Oreziak A, Barriales-Villa R et al (2020) Mavacamten for treatment of symptomatic obstructive hypertrophic cardiomyopathy (EXPLORER-HCM): a randomized, double-blind, placebocontrolled, phase 3 trial. Lancet 396(10253):759-769

6. Papadakis M, Basu J, Sharma S (2020) Mavacamten: treatment aspirations in hypertrophic cardiomyopathy. Lancet 396(10253):736-737

7. Nidorf SM, Fiolet ATL, Mosterd A et al (2020) Colchicine in Patients with Chronic Coronary Disease. NEJM. https://doi. org/10.1056/NEJMoa2021372
8. Liuzzo G, Patrono C (2020) Low-dose colchicine a new tool in the treatment of chronic coronary disease? Comment on the low-dose colchicine (LoDoCo)2 trial. Eur Heart J. https://doi.org/10.1093/ eurheartj/ehaa782

9. Brouwer J, Nijenhuis VJ, Delewi R et al (2020) Aspirin with or without Clopidogrel after Transcatheter Aortic-Valve Implantation. NEJM 383(15):1447-1457

10. Lopes RD, Macedo AVS, de Barros E, Silva PGM et al (2020) Continuing versus suspending angiotensin-converting enzyme inhibitors and angiotensin receptor blockers: Impact on adverse outcomes in hospitalized patients with severe acute respiratory syndrome coronavirus 2 (SARS-CoV-2)-The BRACE CORONA Trial. Am Heart J. 226:49-59. https://doi.org/10.1016/j. ahj.2020.05.002

11. Mathur A, Arnold R, Assmus B et al (2017) The effect of intracoronary infusion of bone marrow-derived mononuclear cells on all-cause mortality in acute myocardial infarction: rationale and design of the BAMI trial. Eur J Heart Fail 19(11):1545-1550. https://doi.org/10.1002/ejhf.829

12. Mathur A, Fernández-Avilés F, Bartunek J et al (2020) The effect of intracoronary infusion of bone marrow-derived mononuclear cells on all-cause mortality in acute myocardial infarction: the BAMI trial. Eur Heart J 41(38):3702-3710. https://doi. org/10.1093/eurheartj/ehaa651

13. Tarantini G, Mojoli M, Varbella F et al (2020) Downstream or upstream administration of $\mathrm{P} 2 \mathrm{Y} 12$ receptor blockers in non-ST elevated acute coronary syndromes: study protocol for a randomized controlled trial. Trials 21(1):966. https://doi.org/10.1186/ s13063-020-04859-1

14. Tarantini G, Mojoli M, Varbella F et al (2020) Timing of Oral $\mathrm{P}_{2} \mathrm{Y}_{12}$ Inhibitor Administration in Patients With Non-ST-Segment Elevation Acute Coronary Syndrome. J Am Coll Cardiol 76(21):2450-2459. https://doi.org/10.1016/j.jacc.2020.08.053 (Epub 2020 Aug 31)

15. Ferrari R, Ford I, Fox K et al (2019) A randomized, double-blind, placebo-controlled trial to assess the efficAcy and safety of Trimetazidine in patients with angina pectoris having been treated by percutaneous coronary intervention (ATPCI study): Rationale, design, and baseline characteristics. Am Heart J 210:98-107. https ://doi.org/10.1016/j.ahj.2018.12.015 (Epub 2019 Jan 15)

16. Ferrari R, Ford I, Fox K et al (2020) Efficacy and safety of trimetazidine after percutaneous coronary intervention (ATPCI): a randomised, double-blind, placebo-controlled trial. Lancet 396(10254):830-838. https://doi.org/10.1016/S0140 $-6736(20) 31790-6$

17. Hindricks G, Potpara T, Dagres N, Arbelo E, Bax JJ, BlomströmLundqvist C, Boriani G, Castella M, Dan GA, Dilaveris PE, Fauchier L, Filippatos G, Kalman JM, La Meir M, Lane DA, Lebeau JP, Lettino M, Lip GYH, Pinto FJ, Thomas GN, Valgimigli M, Van Gelder IC, Van Putte BP, Watkins CL (2020) ESC Guidelines for the diagnosis and management of atrial fibrillation developed in collaboration with the European Association of Cardio-Thoracic Surgery (EACTS). Eur Heart J. https://doi.org/10.1093/eurhe artj/ehaa612

18. Collet JP, Thiele H, Barbato E, Barthélémy O, Bauersachs J, Bhatt DL, Dendale P, Dorobantu M, Edvardsen T, Folliguet T, Gale CP, Gilard M, Jobs A, Jüni P, Lambrinou E, Lewis BS, Mehilli J, Meliga E, Merkely B, Mueller C, Roffi M, Rutten FH, Sibbing D, Siontis GCM (2020) ESC Scientific Document Group ESC Guidelines for the management of acute coronary syndromes in patients presenting without persistent ST-segment elevation. Eur Heart J. https://doi.org/10.1093/eurheartj/ehaa575

19. Pelliccia A, Sharma S, Gati S, Bäck M, Börjesson M, Caselli S, Collet JP, Corrado D, Drezner JA, Halle M, Hansen D, Heidbuchel H, Myers J, Niebauer J, Papadakis M, Piepoli MF, Prescott E, Roos-Hesselink JW, Graham Stuart A, Taylor RS, Thompson 
PD, Tiberi M, Vanhees L, Wilhelm M (2020) ESC Guidelines on sports cardiology and exercise in patients with cardiovascular disease. Eur Heart J. https://doi.org/10.1093/eurheartj/ehaa605

20. Baumgartner H, De Backer J, Babu-Narayan SV, Budts W, Chessa M, Diller GP, Lung B, Kluin J, Lang IM, Meijboom F, Moons P, Mulder BJM, Oechslin E, Roos-Hesselink JW, Schwerzmann M, Sondergaard L, Zeppenfeld K (2020) ESC Scientific Document Group ESC Guidelines for the management of adult congenital heart disease. Eur Heart J. https://doi.org/10.1093/eurheartj/ehaa5 54

Publisher's Note Springer Nature remains neutral with regard to jurisdictional claims in published maps and institutional affiliations. 